Research paper

\title{
T lymphocyte immunophenotypes in the cerebrospinal fluid of dogs with visceral leishmaniasis
}

\author{
Fernanda G. Grano ${ }^{\mathrm{a}}$, José Eduardo dos S. Silva ${ }^{\mathrm{a}}$, Guilherme D. Melo ${ }^{\mathrm{b}}$, Juliana Perosso ${ }^{\mathrm{c}}$, \\ Valéria M.F. Lima ${ }^{c}$, Gisele F. Machado ${ }^{\mathrm{a}, *}$ \\ a Laboratório de Patologia Aplicada (LApap), College of Veterinary Medicine, UNES-Univ Estadual Paulista, Rua Clóvis Pestana, 793 Araçatuba/SP, CEP: \\ 16050-680, Brazil \\ b Laboratoire des Processus Infectieux à Trypanosomatidés, Département Infection et Epidemiologie, Institut Pasteur, 25-28 Rue du Dr Roux, 75724 Paris \\ Cedex 15, France \\ c College of Veterinary Medicine, UNESP-Univ Estadual Paulista, Rua Clóvis Pestana, 793 Araçatuba/SP, CEP: 16050-680, Brazil
}

\section{A R T I C L E I N F O}

\section{Article history:}

Received 11 January 2016

Received in revised form 5 November 2016

Accepted 8 November 2016

\section{Keywords:}

Central nervous system

Inflammation

Leishmania

T-lymphocyte subsets

\begin{abstract}
A B S T R A C T
Visceral leishmaniasis (VL) is a disease causing several clinical manifestations in dogs, including neurological disorders. Nevertheless, there are few studies related to the evaluation of the brain alterations during VL. Evidences of the involvement of cerebral barriers in infected dogs was reported, including the presence of brain inflammatory infiltrate, with a predominance of CD3+ T cells. Therefore, the aim of this study was to determine the immunophenotypes of T lymphocytes in the cerebrospinal fluid (CSF), as well as in peripheral blood, and to correlate with brain alterations in dogs with VL. We detected elevated percentages of double negative (DN) and double positive (DP) T cells in the CSF, with a predominance of TCR $\alpha$ b. In the histopathological analysis, we observed a predominance of lymphoplasmacytic infiltrate, mainly in leptomeninges, ranging from mild to intense, and we observed a positive correlation between the intensity of inflammation in the subependymal area and the DN T cells of the CSF. Thus, the DN T cells seem be acting as villains of the immune system through pro-inflammatory mechanisms. Further, the proportion of the different population of CSF T cells did not differ from those observed in the blood, which provides us with more evidence of blood-CSF barrier breakdown. Together, the results provide more explanation to the inflammation observed in the brain of dogs with VL, which the DN T cells contribute to the origin and progression of the neurological disease. This study provides insight into the immunophenotypes of T lymphocytes in the CSF during canine visceral leishmaniasis.
\end{abstract}

(c) 2016 Elsevier B.V. All rights reserved.

\section{Introduction}

Visceral leishmaniasis (VL) is an anthropozoonosis caused by Leishmania infantum (Syn L. chagasi; Mauricio et al., 2000). In Brazil, dogs are the main hosts of the parasite and can present several clinical manifestations, from subclinical to systemic disorders.

Chronically infected dogs may rarely develop neurological clinical disorders; nevertheless, the pathogenesis of the cerebral form of the VL has still not been elucidated. Infected dogs may present tetraplegy, generalised seizures, walking in circles, vestibular and cerebellar signs, myoclonia and motor incoordination (Font et al., 2004; Ikeda et al., 2007; José-López et al., 2012).

\footnotetext{
* Corresponding author.

E-mail address: giselem@fmva.unesp.br (G.F. Machado).
}

Brain lesions have been described in some reports; the main findings related to canine visceral leishmaniasis were meningitis and choroiditis (Nieto et al., 1996; Viñuelas et al., 2001; Melo et al., 2009, 2013; Melo and Machado, 2011) and the deposition of antigens and immunoglobulins in the central nervous system (CNS) (Garcia-Alonso et al., 1996; Melo et al., 2015a). Multiple brain infarcts were also described in two infected dogs (José-López et al., 2012).

A limited number of reports have pointed to parasite detection together with lesion descriptions. Parasite migration to the meninges (Viñuelas et al., 2001), choroid plexus (Nieto et al., 1996; Márquez et al., 2013) and brain parenchyma (Márquez et al., 2013) was described in a chronically infected dog. Recently, we have detected the presence of $L$. infantum DNA in brain areas (Grano et al., 2014) and up-regulation of the gene expression of some toll-like 
receptors (Melo et al., 2014) within the brain of naturally infected dogs.

The choroid plexi (CP) in the blood-CSF (cerebrospinal fluid) barrier and can prevent the entrance of toxic molecules and drugs into the CNS (Liddelow, 2015). Several bacterias, parasites and viruses such as Neisseria meningitidis, Streptococcus suis, Trypanossoma brucei, Sendai virus, Measles virus, Coxsackievirus B3 (CVB3), AIDS (HIV-1) Echovirus 30 (EV30) and leukaemia (HTLV-1) viruses present tropism for the CP (Levine, 1987; Strazielle and GhersiEgea, 2000; Schwerk et al., 2015). Thereby, these structures can act as an entry route for the Leishmania parasite within the brain. As the brain is a site that is inaccessible for many diagnostic procedures and since there is a proximity of the CSF to brain lesions, the CSF can act as a predictive tool and reflect alterations in the CNS (Duque et al., 2002).

In a previous study performed by our research group, it was observed that dogs with VL presented brain inflammatory infiltrate with a predominance of CD3+ T lymphocytes (Melo et al., 2009), but a low percentage of CD4+ and CD8+ T lymphocytes (Melo et al., 2015b). This suggests that another subset of T cells in the brain might be involved in the triggering of brain inflammation. Furthermore, the leukocyte populations of the CSF differ from those of the blood in healthy dogs, requiring a deeper evaluation of both compartments (Duque et al., 2002).

There are papers describing $\mathrm{T}$ lymphocytes immunophenotypes in dogs, especially in the blood (Tipold et al., 1998; Itoh et al., 2009; Alexandre-Pires et al., 2010; Watabe et al., 2011; Lima et al., 2012), although there are only a few conflicting papers describing the function of double-negative (CD4-CD8- = DN) and double-positive (CD4+CD8+= DP) T cells. In dogs, DP T cells present an activated phenotype and may have unrecognised functions in in vivo immunity and infection, as well as in inflammatory diseases such as allergy, chronic infection, autoimmunity or cancer (Buttlar et al., 2015). TCR $\alpha \beta+D N$ T cells have been connected to autoimmune conditions and present a pro-inflammatory profile. These cells were reported to be increased in several autoimmune/inflammatory disorders (Bleesing et al., 2001; Crispín et al., 2008; Alunno et al., 2013), produce pro-inflammatory cytokines (Crispín et al., 2008), and on the other hand also have regulatory properties (D'Acquisto and Crompton, 2011). With regard to DN cells, there are only a few papers reporting their function, which appear to be conflicting. The DN T cells have potential for a pathogenic role during autoimmunity, acting in the development of disease, as well as for homeostatic role in suppressing excessive immune responses that are deleterious to the host (D'Acquisto and Crompton, 2011). Nevertheless, there are no studies reporting the presence of these cells in the CSF of dogs infected by Leishmania.

Therefore, in view of the paucity of data regarding brain inflammation during $\mathrm{VL}$, and in view of the possible role of T lymphocytes during infection, the aim of this study was to determine the immunophenotypes of T lymphocytes in the CSF of infected dogs and to compare with the same cell populations in peripheral blood. Brain lesions were also evaluated in order to correlate with the $\mathrm{T}$ lymphocytes populations in the CSF.

\section{Material and methods}

\subsection{Animals}

Seventeen naturally infected dogs, eleven male and six female, ranging in age from 1 to 8 years-old, were selected from the Veterinary Teaching Hospital of UNESP, São Paulo State University and from the Zoonosis Control Centre in the municipality of Araçatuba, São Paulo State, Brazil, which is an area endemic for VL. VL diagnosis was achieved using a routine ELISA (enzyme-linked immunosor-

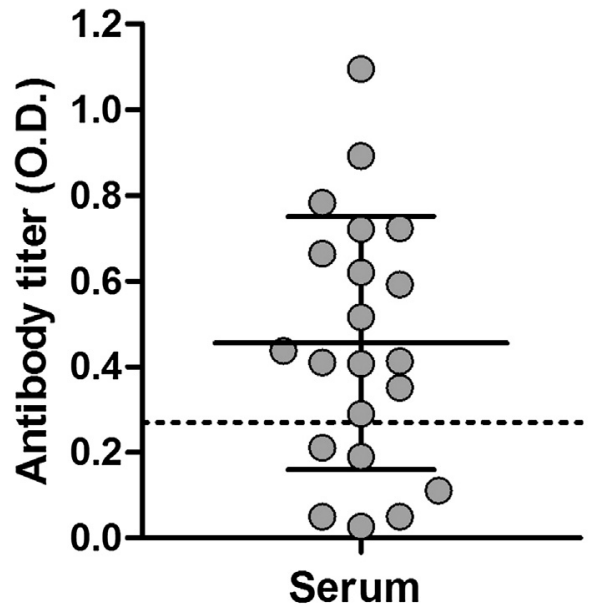

Fig. 1. Scatter plot presenting serum reactivity (IgG) against Leishmania antigens evaluated by ELISA. Anti-L. infantum anti-antibody titers were determined by optical density (O.D.; absorbance at $492 \mathrm{~nm}$ ). Horizontal lines indicate the mean and SD. The dotted lines represent the lower limit of positivity (cut-off): 0.270 .

bent assay) according to Lima et al. (2005). The cut-off point was determined previously with serum from 38 healthy dogs from a non-endemic area, using as reference the mean added by 3 times the standard deviation obtained for the group. The samples were analyzed in duplicate and a blank well (PBS $+0.05 \%$ Tween $20^{\circledR}$ solution) was included in all plates. The ELISA results were confirmed by popliteal lymph node fine-needle aspiration. Of the infected dogs, $64.7 \%(\mathrm{n}=11)$ presented anti-L. infantum IgG antibody titres higher than the cut-off value in sera, ranging from 0.289 to 1.095 (Fig. 1). Moreover, we detected Leishmania amastigotes in all of the dogs through popliteal lymph node fine-needle aspiration.

Dogs were euthanised with the owners' permission, in compliance with state law (São Paulo et al., 2006). None of the animals were previously vaccinated against VL. All animals were symptomatic, with at least three clinical signs. $82.35 \%(n=14)$ of the dogs presented dermatological alterations (seborrhea, generalised alopecia, nasal hyperkeratosis and hypotrichosis), 76.47\% $(\mathrm{n}=13)$ presented generalised lymphadenopathy, $52.94 \%(\mathrm{n}=9)$ presented onychogryphosis, $52.94 \%(n=9)$ presented cachexia, $29.41 \%(n=5)$ presented ophthalmic alterations (conjunctivitis and ocular discharge) and $11.76 \%(n=2)$ presented temporalis muscle atrophy. Nevertheless, they did not present a history of neurological signs and were also serologically negative for toxoplasmosis and neosporosis, as assessed by indirect immunofluorescence assays.

\subsection{Sampling}

The dogs were anesthetised with pentobarbital (Hypnol ${ }^{\circledR}$ ). Peripheral blood samples $(4 \mathrm{ml})$ were obtained from the cephalic vein into tubes with sodium heparin and 5-6 $\mathrm{ml}$ of CSF was collected from the cerebello-medullary cistern. Following that, the animals were euthanised with potassium chloride. Necropsies were performed immediately after euthanasia. The brain was collected and separated into two hemispheres, one of which was placed in $10 \%$ buffered-formalin. After fixation, fragments of some areas (hippocampus, diencephalon, lateral ventricle choroid plexus, midbrain, brainstem, cerebellum and fourth ventricle choroid plexus) were embedded in paraffin and submitted to histological procedures and haematoxylin-eosin (H-E) staining.

The inflammatory lymphoplasmacytic infiltrate was evaluated according to intensity using a ponderal index divided into four grades: Grade 0 (absence of inflammation); Grade 1, mild inflammation (slight inflammatory cell infiltrate mainly at the lep- 
tomeninges and choroid plexus); Grade 2, moderate inflammation (moderate inflammatory cell infiltrate mainly at the leptomeninges and choroid plexus, but with the presence of some perivascular lymphocytes in the brain tissue); and Grade 3, intense inflammation (remarkable inflammatory cell infiltrate mainly at the leptomeninges and choroid plexus plus intense perivascular infiltration in the brain tissue).

\subsection{Flow cytometry analysis}

Peripheral blood samples were submitted to the separation of mononuclear cells on a Ficoll-Paque ${ }^{\mathrm{TM}}$ gradient (Amersham Biosciences, Piscataway, NJ, USA), in accordance with the manufacturer's recommendations. After this, the red blood cells were lysed by adding $5 \mathrm{ml}$ of lysis buffer $(0.16 \mathrm{M} \mathrm{NH} 4 \mathrm{Cl}$ and $0.17 \mathrm{M}$ Tris) to the isolated cells and incubating at $4{ }^{\circ} \mathrm{C}$ for $10 \mathrm{~min}$. The cells were washed three times adding $30 \mathrm{ml}$ of PBS $(10 \mathrm{~min}$ at $400 \times \mathrm{g})$ at $20^{\circ} \mathrm{C}$. CSF was centrifuged at $400 \times g$ for $10 \mathrm{~min}$. The pellets were transferred into a $1.5 \mathrm{ml}$ microcentrifuge tube and resuspended in $1 \mathrm{ml}$ of PBS. The centrifugation was repeated three times. Each sample was individually processed.

The cellular concentration of blood and CSF was adjusted individually to $10^{5}$ cells in $100 \mu$ l of phosphate-buffered saline solution for each dog sample. The cells were incubated for $60 \mathrm{~min}$ at $4{ }^{\circ} \mathrm{C}$ with monoclonal anti-dog antibodies: FITC-labelled anti-CD3 (clone CA17.2A12), RPE-labelled anti-CD4 (clone YKIX302.9), Alexa Fluor ${ }^{\circledR}$ 647-labelled anti-CD8 (clone YCATE55.9) (Serotec, UK), antiTCR $\alpha \beta$ (clone CA15.8G7) and anti-TCR $\gamma d$ (clone CA20.8H1) (UC Davis, USA). Following this, secondary antibodies conjugated to FITC (TCR $\alpha \beta)$ or RPE (TCR $\gamma \delta$ ) were used (Abcam, UK). Isotype controls (Serotec, UK) were used to delimit the negative populations of the stained cells. Following antibody incubation, washing was performed with PBS ( $\mathrm{pH} 7.0$ ) and the cells were resuspended in fixation buffer ( $10 \%$ formaldehyde).

To analyse the different immunostained populations in a Guava Easy-CyteMini system by using CytoSoft software, 10,000 events were acquired in accordance with the recommendations in the Guava PCA User's Guide and respective package inserts. The values obtained for healthy dogs from the literature, according to Tipold et al. (1998), Duque et al. (2002), Itoh et al. (2009), Alexandre-Pires et al. (2010), Watabe et al. (2011) and Lima et al. (2012), were used as reference values for this study.

\subsection{Statistical analysis}

The statistical evaluation between blood and CSF was performed by the Wilcoxon test. T lymphocyte subset analysis in CSF and blood and inflammation intensity analysis in the brain were performed using the Friedman test, followed by Dunn's test. The Spearman test was performed to correlate the blood and CSF cells with the intensity of brain lesions. Statistical significance was accepted when $P<0.05$. All statistical analyses were performed using Prism software (Prism 6, GraphPad).

\subsection{Ethical issues}

This study was approved by the institutional Ethics and Animal Welfare Committee (CEEA - Comissão de Ética e Experimentação Animal, UNESP, process \#01463-2012).

\section{Results}

\subsection{Immunophenotyping of T lymphocytes}

The quantification of $\mathrm{T}$ lymphocytes was carried out according to the fluorescence of CD3+ cells. The CD4+, CD8+, DN and DP cells subsets were identified and quantified within the CD3+ T lymphocytes population (Fig. 2), while TCRs were quantified in relation to the total count of mononuclear cells.

When we compared the CD3+ T cells percentage between CSF and blood (Fig. 3A) we observed that there was no statistical difference, or for all of the subtypes of $\mathrm{T}$ cells evaluated, that were present in similar proportions in these compartments $(P>0.05)$. A predominance of TCR $\alpha \beta$ lymphocytes in both, blood and CSF was observed $(P<0.0001)$, whereas the TCR $\gamma \delta$ cells were found at a lower percentage (Figs. 3B and C). Moreover, the predominant Tlymphocytes subsets in the CSF were the DN cells (Fig. 3D), although there was no difference between DN and DP cells in this compartment. Furthermore, there was no difference between the percentage of CD4+ and CD8+ cells and between CD4+ and DP cells in the CSF. In both the blood and CSF, it was verified that CD8+ T cells were lower when compared to the DN T lymphocytes and there was no difference between the percentage of CD4+, CD8+ and DP cells or CD4+, DP and DN cells in the blood (Fig. 3E). Moreover, the mean percentages of all $\mathrm{T}$ cells populations were lower in relation to the reference values, except for DP and DN percentages, that were higher in the blood (Table 1).

\subsection{Evaluation of the inflammatory infiltrate in the brain}

Histopathological analysis revealed mononuclear cells infiltrate, especially composed of lymphocytes, plasma cells and few histiocytes in the choroid plexus and leptomeninges and lymphocytes and plasma cells in periventricular areas, with inflammation intensity ranging from mild to intense. The leptomeninges were the site with the highest concentration of inflammatory cells, differing from the other areas evaluated, and there was no difference in the intensity of the inflammatory infiltrate between the choroid plexus and subependymal area. Fig. 4 shows the representative photomicrographs of inflammatory infiltrate in brain areas, according to the intensity of inflammation.

In leptomeninges, $58.8 \%$ of the dogs $(n=10)$ presented moderate infiltration of inflammatory cells, $35.3 \%(n=6)$ presented mild inflammatory infiltrate and $5.9 \%(n=1)$ presented severe inflammatory infiltrate. In the subependymal area, $64.7 \%(n=11)$ of the animals had mild inflammatory infiltrate, $11.8 \%(n=2)$ presented moderate intensity and $23.5 \%(n=4)$ showed no inflammatory infiltrate. In the choroid plexus, $35.3 \%(n=6)$ of the dogs presented mild inflammatory infiltrate, $17.6 \%(n=3)$ showed moderate inflammatory infiltrate, $5.9 \%(n=1)$ presented severe intensity of inflammatory cells and $41.2 \%(n=7)$ showed no inflammatory infiltrate. In the study presented here, we did not observe amastigotes of Leishmania in the H-E stained nervous tissue samples.

\subsection{Correlation of the Tlymphocytes immunophenotypes with the intensity of brain inflammation}

There was no correlation between the investigated immunophenotypes of $\mathrm{T}$ lymphocytes of the CSF and the intensity of inflammation in the leptomeninges. However, in the choroid plexus, a weak negative correlation was observed between DP cells from the CSF and the intensity of inflammation (Fig. 5A). The other cell types did not present any correlation. Also, in the subependymal area, there was a moderate negative correlation of the inflammatory infiltrate intensity with DP and CD8+ cells (Fig. 5B and D), and weak negative correlation with CD4+ (Fig. 5C) of the CSF. Still, for the DN cells, moderate positive correlation with inflammation was observed (Fig. 5E).

Correlation of the amount of blood mononuclear cells with inflammation intensity in the brain was also performed, but there were no correlations between these parameters. 

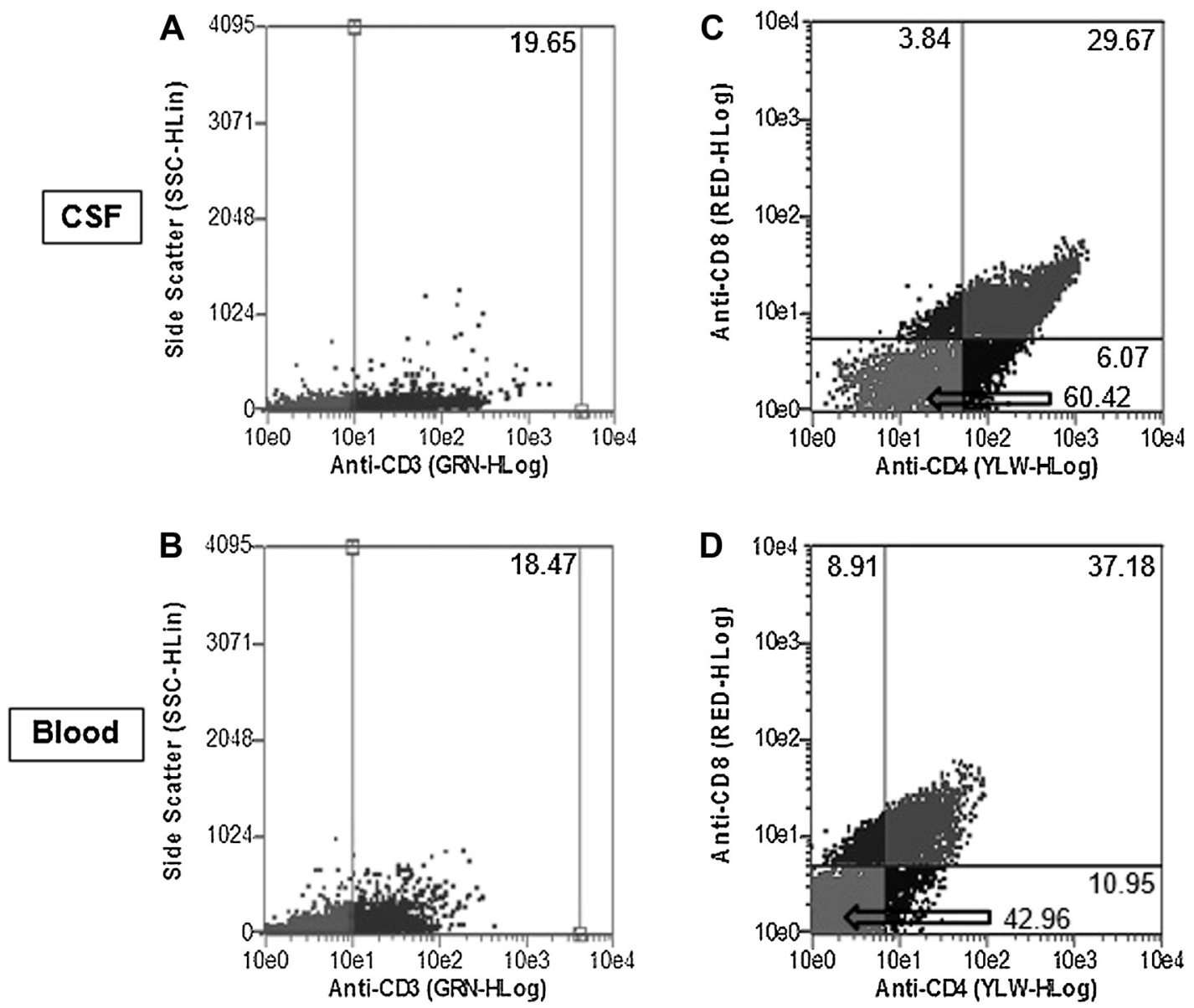

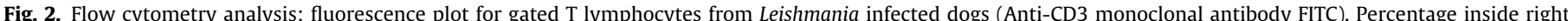

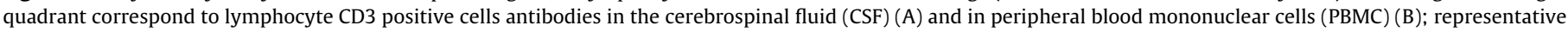

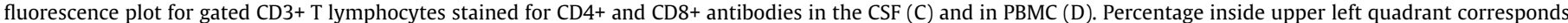

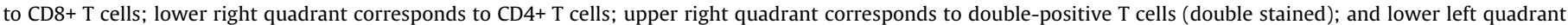
corresponds to double-negative T cells.
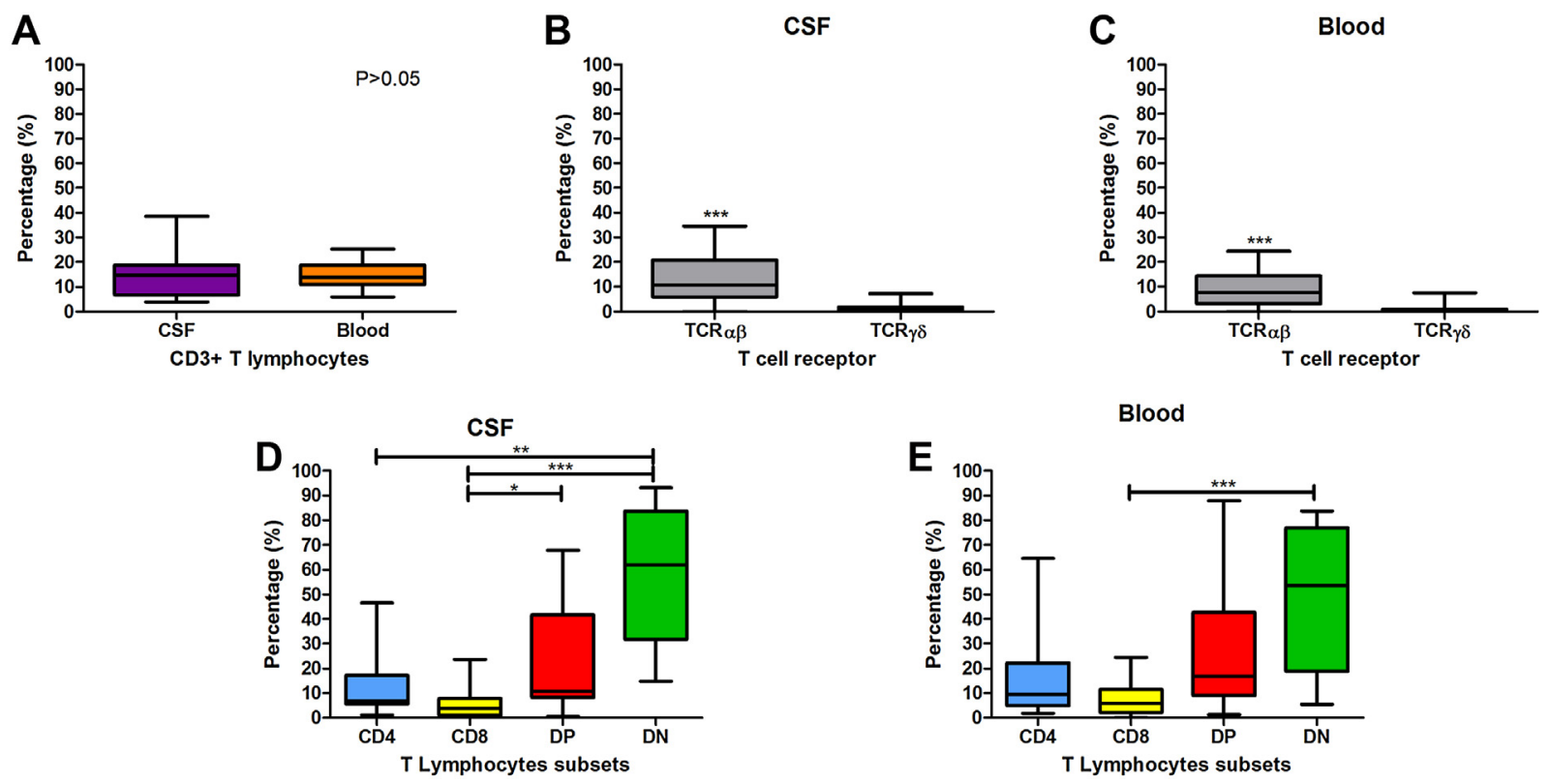

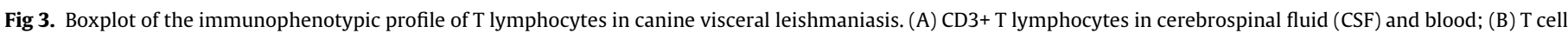

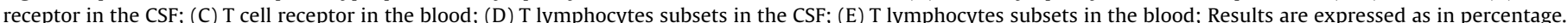
Significant difference by Dunn's multiple comparison test is indicated by ${ }^{*}(\mathrm{P}<0.05),{ }^{* *}(\mathrm{P}<0.01)$ and ${ }^{* * *}(\mathrm{P}<0.001)$. 

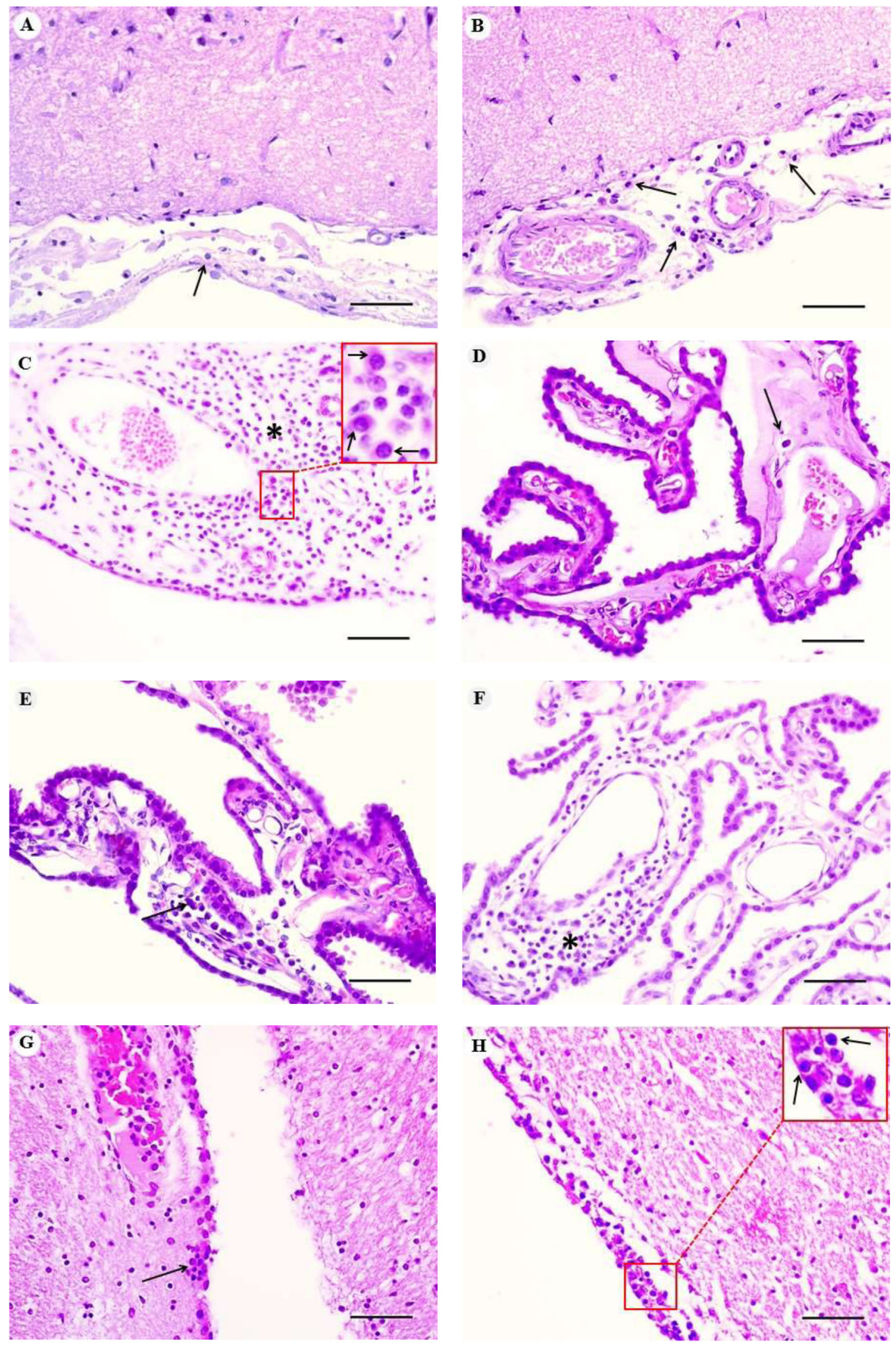

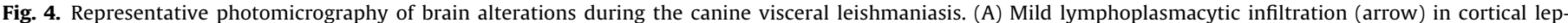

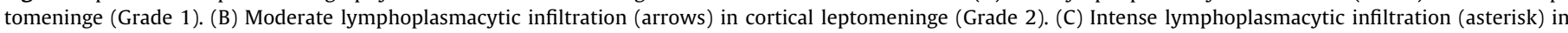

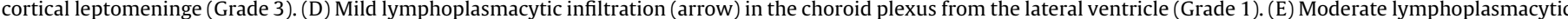

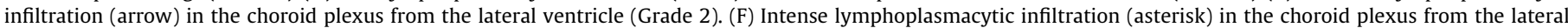

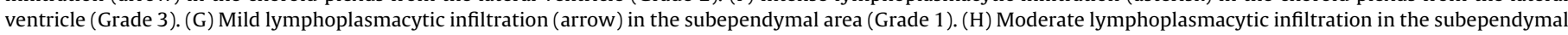
area (Grade 2). Inset: mononuclear cells amplified. Hematoxylin and Eosin. Scale bar $=50 \mu \mathrm{m}$. 
Table 1

Lymphocyte subsets of cerebrospinal fluid (CSF) and peripheral blood in infected dogs and in healthy dogs in percentage (\%) (mean \pm standard deviation).

\begin{tabular}{|c|c|c|c|c|}
\hline \multirow[t]{2}{*}{ Populations } & \multicolumn{2}{|l|}{ CSF } & \multicolumn{2}{|l|}{ Blood } \\
\hline & Infected dogs & Reference values & Infected dogs & Reference values \\
\hline \multirow[t]{3}{*}{ CD3+ } & & & & $68.0 \pm 10.0^{a}$ \\
\hline & $15.1 \pm 9.1$ & $53.0 \pm 11.0^{\mathrm{a}}$ & $14.8 \pm 5.2$ & $70.0^{\mathrm{b}}$ \\
\hline & & & & $80.6 \pm 5.0^{c}$ \\
\hline \multirow[t]{2}{*}{ CD4+ } & $11.8 \pm 10.9$ & $28.6 \pm 12.4^{\mathrm{d}}$ & $13.4 \pm 18.0$ & $39.1 \pm 10.7^{e}$ \\
\hline & & $34.0 \pm 8.0^{\mathrm{a}}$ & & $40.1 \pm 5.6^{\mathrm{f}}$ \\
\hline \multirow[t]{2}{*}{ CD8+ } & $6.1 \pm 7.1$ & $22.0 \pm 13.6^{\mathrm{d}}$ & $8.2 \pm 7.9$ & $22.1 \pm 8.4^{\mathrm{e}}$ \\
\hline & & $25.0 \pm 19.0^{\mathrm{a}}$ & & $22.2 \pm 2.9^{f}$ \\
\hline DN & $59.0 \pm 26.6$ & - & $49.2 \pm 27.3$ & $25.7^{\mathrm{b}, \mathrm{g}}$ \\
\hline DP & $23.1 \pm 21.9$ & - & $26.1 \pm 23.6$ & $1.5^{\mathrm{b}, \mathrm{g}}$ \\
\hline $\mathrm{TCR} \alpha \beta$ & $13.6 \pm 10.8$ & $54.0 \pm 17.0^{\mathrm{a}}$ & $9.3 \pm 7.1$ & $66.0 \pm 11.0^{\mathrm{a}}$ \\
\hline TCR $\gamma \delta$ & $1.4 \pm 2.1$ & $4.5 \pm 6.0^{\mathrm{a}}$ & $0.9 \pm 1.9$ & $3.2 \pm 2.8^{\mathrm{a}}$ \\
\hline
\end{tabular}

a Tipold et al. (1998).

b Alexandre-Pires et al. (2010).

c Lima et al. (2012).

d Duque et al. (2002).

e Watabe et al. (2011).

f Itoh et al. (2009).

$\mathrm{g}$ Representative values from one dog.
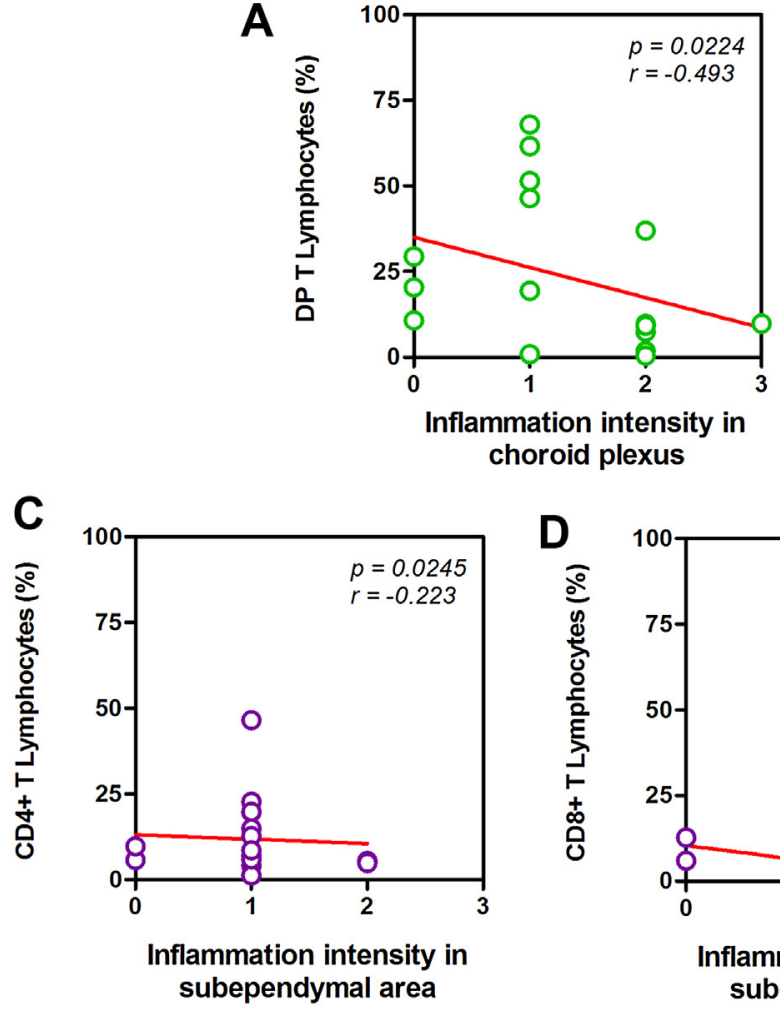

B
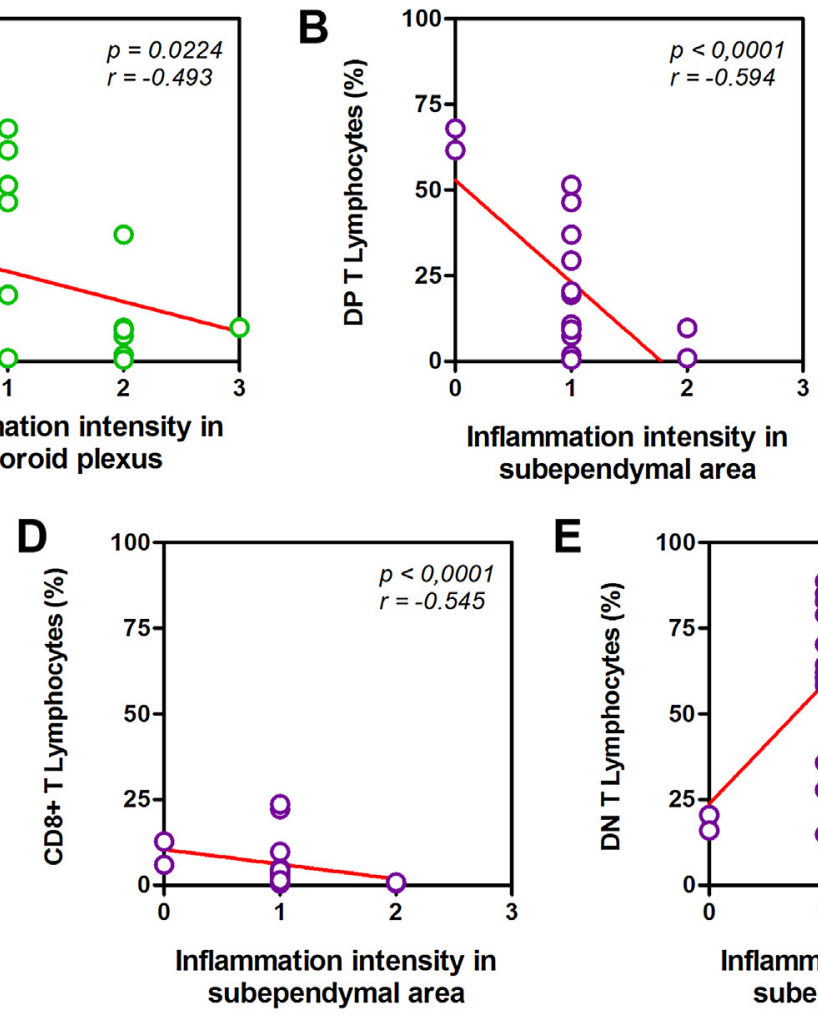

$E$

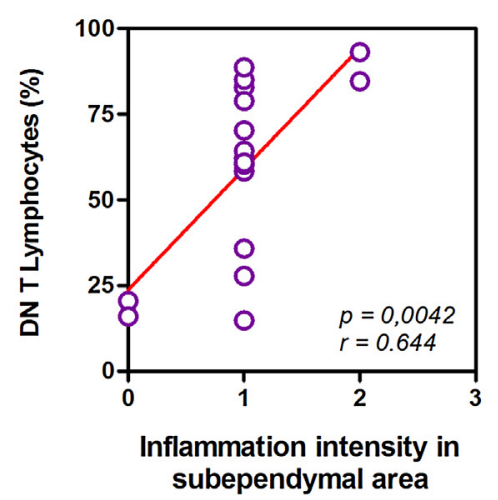

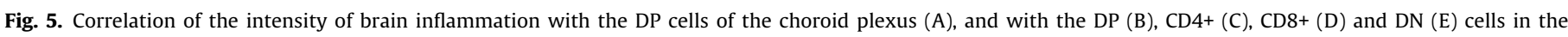
subependymal area.

\section{Discussion}

We observed a low number of CD3+ T lymphocytes in the CSF, as well as CD4+ and CD8+ T single positive (SP) lymphocytes, indicating that these cells are reduced during the canine VL when compared to the values for healthy dogs (Tipold et al., 1998; Duque et al., 2002). The reduction of T cell number may occur in the CSF, as well as in others sites, such as the spleen and peripheral blood, due to the high level of apoptosis in these cells (Lima et al., 2012; Perosso et al., 2014), or T cells exhaustion, a state of T cell dysfunc- tion that arises during many chronic infections and cancer (Wherry, 2011).

Although there was a reduction in the total amount of $\mathrm{T}$ cells, we verified a predominance of DN and DP T cells in the CSF. During normal T-lymphocyte development in the thymus, DN cells originate the DP cells, which differentiate to mature CD4+ or CD8+ SP cells (D'Acquisto and Cromptom, 2011). The low number of SP cells observed in the infected dogs of our study may be due to acquisition of the DP phenotype outside of the thymus or due to the liberation of immature cells into the bloodstream. The CD4+ and CD8+ cells can act as progenitors of DP cells, as described previously in dogs 
(Bismarck et al., 2014), as well as in swine (Saalmuller et al., 2002) and humans (Blue et al., 1986; Nascimbeni et al., 2004; Parel and Chizzolini, 2004; Schenkel et al., 2010). The extrathymic origin of DP T cells was reported in several others species, such as mice, rats, chickens, monkeys, swine and humans, and there appears to be no predilection of localisation, as reviewed by Overgaard et al. (2015).

We observed that there was a predominance of lymphocytes expressing TCR $\alpha \beta$ in the CSF, which also occurs in healthy dogs (Tipold et al., 1998). This phenotype was reported predominantly in the tissues of healthy dogs, as intestinal lamina propria (German et al., 1999), respiratory tract and in the alveolar interstitium of dogs, while TCR $\gamma \delta$ cells were absent or present in a very low number (Peeters et al., 2005). Thereby, the $\gamma \delta$ T cells seem to represent a small population of cells, which is consistent with the results obtained. The recruitment of $\gamma \delta$ T cells during inflammation has been reported during canine atopic dermatitis (Olivry et al., 1997) and in the inflamed uteruses of bitches affected by pyometra (Bartoskova et al., 2012). Until now, these cells seem do not be related to any brain inflammation in dogs, although a recent review by Malik et al. (2016) showed the presence of $\gamma \delta$ T cells in the brain of humans with multiple sclerosis, but their function during disease activity is not clearly understood.

Moreover, we have observed that all immunophenotypes of the $\mathrm{T}$ lymphocytes analysed were present in similar proportions when comparing the CSF and peripheral blood, with no difference between these two compartments. In contrast, in healthy dogs, there is a higher proportion of CD4+ cells in the blood than in the CSF (Duque et al., 2002). This difference might occur because the CD4+ cells can have an important role in the immune response in healthy dogs and they are fundamental for the development of an effective immune response, and a low number of these cells appears to contribute to parasite replication, indicating a poor prognosis of disease progression (Leal et al., 2014).

The high variability of the obtained results in this study may be because of the dogs were naturally infected. In a previous research we observed that brain inflammation may occur in symptomatic or asymptomatic dogs (Melo et al., 2009). It is possible that this variability was reduced if we had evaluated the parameters necessary to separate the dogs into groups, according to the clinical score, as established by Solano-Gallego et al. (2011).

Furthermore, we have previously reported disruption of the blood-brain barrier (BBB) in other dogs with visceral leishmaniasis (Melo et al., 2015a) and findings by our research group have supported the hypothesis that a breakdown of the blood-CSF barrier is also occurring (Melo et al., 2009; Machado et al., 2010; Marangoni et al., 2011). There is also evidence of alterations in the selective filtering of the blood CSF-barrier, caused by peripheral inflammatory processes; Lima et al. (2003) observed a strong correlation of antibody titres in the sera and in the CSF of dogs with VL, proposing the passage of these antibodies and antigens from the blood to the CSF compartment. Since cells of the blood and CSF of this study are present in similar proportions, breakdown of the blood-CSF barrier breakdown might be allowing the passage of cells from the blood to the CSF, which CP may act as a source of T cells for the CSF or to the adjacent brain areas (Petito and Adkins, 2005).

Although Nieto et al. (1996) and Viñuelas et al. (2001) found the presence of amastigotes of $L$. infantum in the meninges and choroid plexus, we did not observe the presence of the parasite in the studied brain areas. Nevertheless, all dogs in this study showed mild to intense mononuclear cell infiltration in all three brain areas evaluated, but mainly in the leptomeninges. Meningitis and choroiditis are common findings during canine VL (Nieto et al., 1996; Viñuelas et al., 2001; Melo et al., 2009, 2013; Melo and Machado, 2009; Márquez et al., 2013). In order to explain the origin of the brain inflammatory cells, it was decided to search for corre- lation between the T lymphocyte populations present in the CSF and the histopathological alterations.

The negative correlation of the intensity of inflammation in the subependymal area with the DP and SP cells, as well as the negative correlation observed in the choroid plexus for the DP T cells of the CSF, show that these cells are present in higher amounts in dogs with a mild intensity of inflammation, and probably stimulate anti-inflammatory mechanisms in the initial phase of brain inflammation. The higher level of SP cells has been associated with the protection and control of infection in the canine VL (Pinelli et al., 1995; Reis et al., 2006; Coura-Vital et al., 2011; Leal et al., 2014). DP cells acting against the infection was reported by AlexandrePires et al. (2010) in dogs with VL, who detected a reduction of these cells in the bone marrow of treated dogs and suggested that they might be retained in other organs, inhibiting the replication of parasites. Moreover, data from Bismarck et al. (2012) link the phenotype of canine CD4+CD8+T cells to activated effector/memory cells. Canine DP cells are present in lower amount, but are more heterogeneous than porcine ones, consisting of a small proportion of CD8 cells expressing the $\beta$ chain in addition to the $\alpha$ chain, similarly to human CD4+CD8+ T cells (Bismarck et al., 2012); however, as canine DP T cells appear to be unique compared to other species, more investigation is necessary to determine their possible role in the canine immune response (Buttlar et al., 2015), particularly when considering the brain milieu.

On the other hand, DN T cells seem to act as villains of the immune system in the CSF of dogs in this study by promoting inflammation, considering the positive correlation observed between the intensity of inflammation in the subependymal area and the proportion of DN T cells of the CSF. These cells produce inflammatory cytokines, such as IL-17 and IFN- $\gamma$ (Cowley et al., 2010; Crispín et al., 2008) and have been reported to play a key role in various models of infection (D'Acquisto and Cromptom, 2011). Upregulation of the gene expression of IFN- $\gamma$ in the brain, as well as other inflammatory cytokines have been detected in a previous study performed by our research group (Melo et al., 2013), indicating that the brain has potential to produce these cytokines locally, contributing to the inflammation. Alexandre-Pires et al. (2010) also reported the frequencies of DN $\mathrm{T}$ cells in the peripheral blood of dogs with VL, but in a low frequency in asymptomatic animals. They suggested that the presence of Leishmania induces a downregulation of these cells. This hypothesis is in agreement with our results, where we have found a high frequency of these cells in the brain, along with the absence of the parasite.

Furthermore, we have observed no correlation between the population of T cells in the CSF with the intensity of inflammation in the leptomeninges. It is possible that the inflammation observed in leptomeninges has different phenotypic composition. Previous works characterised the presence of T lymphocytes, B lymphocytes, phagocytic cells, plasm cells and polymorphonuclear cells in the inflammatory meningeal infiltrate during canine VL(Viñuelas et al., 2001; Melo et al., 2009).

\section{Conclusions}

In the data presented here, we describe insight into the immunophenotypes of T lymphocytes in the CSF and, particularly, about the possible role of DN and DP T cells in coordinate the brain inflammation during VL. We verified that infected dogs present similar proportions of T cells in both the blood and CSF, which may be related to the breakdown of the brain and CSF barriers. Moreover, the higher number of DN T cells in dogs with more severe brain inflammation indicates that these cells somehow are contributing to the brain lesions. Further, we suggest that the levels of 
DN and DP T cells in the CSF may be indicative of the stage of brain inflammation.

\section{Conflict of interest statement}

The authors of this work do not have any financial, personal or other relationship with organizations or people that could inadequately influence the content of this paper.

\section{Acknowledgments}

F.G. Grano was supported by a Master's degree scholarship from the Fundação de Amparo à Pesquisa do Estado de São Paulo(FAPESP, grant number 2011/03504-4). The research project was also supported by FAPESP, grant number 2012/01540-0.

\section{References}

Alexandre-Pires, G., de Brito, M.T., Algueró, C., Martins, C., Rodrigues, O.R., da Fonseca, I.P., Santos-Gomes, G., 2010. Canine leishmaniasis. Immunophenotypic profile of leukocytes in different compartments of symptomatic, asymptomatic and treated dogs. Vet. Immunol. Immunopathol. 137 (3-4), 275-283.

Alunno, A., Bistoni, O., Bartoloni Bocci, E., Caterbi, S., Bigerna, B., Pucciarini, A., Tabarrini, A., Mannucci, R., Beghelli, D., Falini, B., Gerli, R., 2013. IL-17-producing double-negative T cells are expanded in the peripheral blood, infiltrate the salivary gland and are partially resistant to corticosteroid therapy in patients with Sjögren's syndrome. Reumatismo 65, 192-198.

Bartoskova, A., Turanek-Knotigova, P., Matiasovic, J., Oreskovic, Z., Vicenova, M. Stepanova, H., Ondrackova, P., Vitasek, R., Leva, L., Moore, P.F., Faldyna, M., 2012. $\gamma \delta$ T lymphocytes are recruited into the inflamed uterus of bitches suffering from pyometra. Vet. J. 194 (3), 303-308.

Bismarck, D., Schutze, N., Moore, P., Buttner, M., Alber, G., Buttlar, H., 2012. Canine CD4+ CD8+ double positive T cells in peripheral bloodhave features of activated T cells. Vet. Immunol. Immunopathol. 149, 157-166.

Bismarck, D., Moore, P.F., Alber, G., Buttlar, H., 2014. Canine CD4+ CD8+ double-positive T cells can develop from CD4+ and CD8+ T cells. Vet. Immunol. Immunopathol. 162, 72-82.

Bleesing, J.J., Brown, M.R., Dale, J.K., Straus, S.E., Lenardo, M.J., Puck, J.M., Atkinson, T.P., Fleisher, T.A., 2001. TcR-alpha/beta(+) CD4(-)CD8(-) T cells in humans with the autoimmune lymphoproliferative syndrome express a novel CD45 isoform that is analogous to murine B220 and represents a marker of altered O-glycan biosynthesis. Clin. Immunol. 100, 314-324.

Blue, M.L., Daley, J.F., Levine, H., Craig, K.A., Schlossman, S.F., 1986. Biosyn-thesis and surface expression of T8 by peripheral blood T4+ cells in vitro. J. Immunol. 137, 1202-1207

Buttlar, H., Bismarck, D., Alber, G., 2015. Peripheral canine CD4+ CD8+ double-positive T cells - unique amongst others. Vet. Immunol. Immunopathol. 168, 169-175.

Coura-Vital, W., Marques, M.J., Giunchetti, R.C., Teixeira-Carvalho, A., Moreira, N.D. Vitoriano-Souza, J., Vieira, P.M., Carneiro, C.M., Côrrea-Oliveira, R. Martins-Filho, O.A., Carneiro, M., Reis, A.B., 2011. Humoral and cellular immune responses in dogs with inapparent natural Leishmania infantum infection. Vet. J. 190, e43-e47.

Cowley, S.C., Meierovics, A.I., Frelinger, J.A., Iwakura, Y., Elkins, K.L., 2010. Lung CD4-CD8 - double-negative T cells are prominent producers of IL-17A and IFN-gamma during primary respiratory murine infection with Francisella tularensis live vaccine strain. J. Immunol. 184 (10), 5791-5801.

Crispín, J.C., Oukka, M., Bayliss, G., Cohen, R.A., Van Beek, C.A., Stillman, I.E., Kyttaris, V.C., Juang, Y.T., Tsokos, G.C., 2008. Expanded double negative T cells in patients with systemic lupus erythematosus produce IL-17 and infiltrate the kidneys. J. Immunol. 181, 8761-8766.

D'Acquisto, F., Crompton, T., 2011. CD3+CD4-CD8-(double negative) T cells: sSaviours or villains of the immune response? Biochem. Pharmacol. 82 (4), 333-340.

Duque, C., Parent, J., Bienzle, D., 2002. The immunophenotype of blood and cerebrospinal fluid mononuclear cells in dogs. J. Vet. Intern. Med. 16, 714-719.

Font, A., Mascort, J., Altimira, J., Closa, J.M., Vilafranca, M., 2004. Acute paraplegia associated with vasculitis in a dog with leishmaniasis. J. Small Anim. Pract. 45, 199-201.

Garcia-Alonso, M., Nieto, A.G., Blanco, A., Requena, J.M., Alonso, C., Navarrete, I., 1996. Presence of antibodies in the aqueous humour and cerebrospinal fluid during Leishmania infections in dogs. Pathological features at the central nervous system. Parasite Immunol. 18, 539-546.

German, A.J., Hall, E.J., Moore, P.F., Ringler, D.J., Newman, W., Day, M.J., 1999. The distribution of lymphocytes expressing $\alpha \beta$ and $\gamma \delta$ T-cell receptors, and the expression of mucosal addressin cell adhesion molecule- 1 in the canine intestine. J. Comp. Pathol. 121, 249-263.
Grano, F.G., Melo, G.D., Belinchón-Lorenzo, S., Gómez-Nieto, L.C., Machado, G.F., 2014. First detection of Leishmania infantum DNA within the brain of naturally infected dogs. Vet. Parasitol. 204, 376-380.

Ikeda, F.A., Laurenti, M.D., Corbett, C.E., Feitosa, M.M., Machado, G.F., Perry, S.H.V 2007. Histological and immunohistochemical study of the central nervous system of dogs naturally infected by Leishmania (Leishmania) chagasi. Braz. J. Vet. Res. Anim. Sci. 44, 5-11.

Itoh, H., Horiuchi, Y., Nagasaki, T., Sakonju, I., Kakuta, T., Fukushima, U., Uchide, T. Yamashita, M., Kuwabara, M., Ysa, S., Takase, K., 2009. Evaluation of immunological status in tumor-bearing dogs. Vet. Immunol. Immunopathol. 132, 85-90.

José-López, R., De la Fuente, C., Añor, S., 2012. Presumed brain infarctions in two dogs with systemic leishmaniasis. J. Small Anim. Pract. 53, 554-557.

Leal, G.G., Roatt, B.M., Aguiar-Soares, R.D.O., Carneiro, C.M., Giunchetti, R.C. Teixeira-Carvalho, A., Martins-Filho, O.A., Francisco, A.F., Cardoso, J.M., Mathias, F.A.S., Correa-Oliveira, R., Carneiro, M., Coura-Vital, W., Reis, A.B., 2014. Immunological profile of resistance and susceptibility in naturally infected dogs by Leishmania infantum. Vet. Parasitol. 205, 472-482.

Levine, S., 1987. Choroid plexus: target for systemic diseases and pathway to the brain. Lab. Invest. 56, 231-233.

Liddelow, S.A., 2015. Development of the choroid plexus and blood-CSF barrier Front. Neurosci. 9 (32), 1-13.

Lima, V.M.F., Gonçalves, M.E., Ikeda, F.A., Luvizotto, M.C.R., Feitosa, M.M., 2003. Anti-Leishmania antibodies in cerebrospinal fluid from dogs with visceral leishmaniasis. Braz. J. Med. Biol. Res. 36, 485-489.

Lima, V.M.F., Biazzono, L., Silva, A.C., Correa, A.P.F.L., Luvizotto, M.C.R., 2005 Serological diagnosis of visceral leishmaniasis by an enzyme immunoassay using protein A in naturally infected dogs. Braz. J. Vet. Res. Anim. Sci. 25 (4) 215-218.

Lima, V.M.F., Fattori, K.R., Souza de, F., Eugênio, F.R., Santos dos, P.S.P., Rozza, D.B., Machado, G.F., 2012. Apoptosis in T lymphocytes from spleen tissue and peripheral blood of L. (L.) chagasi naturally infected dogs. Vet. Parasitol. 184, $147-153$.

Márquez, M., Pedregosa, J.R., López, J., Marco-Salazar, P., Fondevila, D., Pumarola, M., 2013. Leishmania amastigotes in the central nervous system of a naturally infected dog. J. Vet. Diagn. Invest. 25 (1), 142-146.

Machado, G.F., Melo, G.D., Moraes, O.C., Souza, M.S., Marcondes, M., Perri, S.H., Vasconcelos, R.O., 2010. Differential alterations in the activity of matrix metalloproteinases within the nervous tissue of dogs in distinct manifestations of visceral leishmaniasis. Vet. Immunol. Immunopathol. 136, 340-345.

Malik, S., Want, M.Y., Awasthi, A., 2016. The emerging roles of gamma-delta T cells in tissue inflammation in experimental autoimmune encephalomyelitis. Front. Immunol. 7, 14

Marangoni, N.R., Melo, G.D., Moraes, O.C., Souza, M.S., Perri, S.H., Machado, G.F., 2011. Levels of matrix metalloproteinase-2 and metalloproteinase-9 in the cerebrospinal fluid of dogs with visceral leishmaniasis. Parasite Immunol. 33, 330-334.

Mauricio, I.L., Stothard, J.R., Miles, M.A., 2000. The strange case of Leishmania chagasi. Parasitol. Today 16, 188-189.

Melo, G.D., Machado, G.F., 2009. Choroid plexus involvement in dogs with spontaneous visceral leishmaniasis: a histopathological investigation. Braz. J. Vet. Pathol. 2 (2), 69-74

Melo, G.D., Machado, G.F., 2011. Glial reactivity in dogs with visceral leishmaniasis: correlation with $\mathrm{T}$ lymphocyte infiltration and with cerebrospinal fluid anti-Leishmania antibody titres. Cell Tissue Res. 346, 293-304.

Melo, G.D., Marcondes, M., Vasconcelos, R.O., Machado, G.F., 2009. Leukocyte entry into the CNS of Leishmania chagasi naturally infected dogs. Vet. Parasitol. 162 248-256.

Melo, G.D., Seraguci, T.F., Schweigert, A., Silva, J.E.S., Grano, F.G., Peiró, J.R., Lima, V.M.F., Machado, G.F., 2013. Pro-inflammatory cytokines predominate in the brains of dogs with visceral leishmaniasis: a natural model of neuroinflammation during systemic parasitic infection. Vet. Parasitol. 192, 57-66.

Melo, G.D., Silva, J.E.S., Grano, F.G., Homem, C.G., Machado, G.F., 2014 Compartmentalized gene expression of toll-like receptors 2, 4 and 9 in the brain and peripheral lymphoid organs during canine visceral leishmaniasis. Parasite Immunol. 36, 726-731.

Melo, G.D., Grano, F.G., Silva, J.E.S., Kremer, B.E., Lima, V.M.F., Machado, G.F., 2015a. Blood-brain barrier disruption during spontaneous canine visceral leishmaniasis. Parasite Immunol. 37 (12), 635-645.

Melo, G.D., Silva, J.E.S., Grano, F.G., Souza, M.S., Machado, G.F., 2015b. Leishmania infection and neuroinflammation: specific chemokine profile and absence of parasites in the brain of naturally-infected dogs. J. Neuroimmunol. 289, 21-29.

Nascimbeni, M., Shin, E.C., Chiriboga, L., Kleiner, D.E., Rehermann, B., 2004. Peripheral CD4_CD8_ T cells are differentiated effector memory cells with antiviral functions. Blood 104 (2), 478-486.

Nieto, C.G., Viñuelas, J., Blanco, A., Garcia-Alonso, M., Verdugo, S.G., Navarrete, I., 1996. Detection of Leishmania infantum amastigotes in canine choroid plexus. Vet. Rec. 139, 346-347.

Olivry, T., Naydan, D.K., Moore, P.F., 1997. Characterization of the cutaneous inflammatory infiltrate in canine atopic dermatitis. Am. J. Dermatopathol. 19 (5), 477-486.

Overgaard, N.H., Jung, J.W., Steptoe, R.J., Wells, J.W., 2015. CD4+/CD8+ double-positive T cells: more than just a developmental stage? J. Leukoc. Biol. 97, 31-38. 
Parel, Y., Chizzolini, C., 2004. CD4+ CD8+ double positive (DP) T cells in health and disease. Autoimmun. Rev. 3, 215-220.

Peeters, D., Day, M.J., Farnir, F., Moore, P., Clercx, C., 2005. Distribution of leucocyte subsets in the canine respiratory tract. J. Comp. Pathol. 132, 261-272.

Perosso, J., Silva, K.L.O., Ferreira, S.I., Avanço, S.V., Santos, P.S.P., Eugênio, F.R., Almeida, B.F.M., Lima, V.M.F., 2014. Alteration of sFAS and sFAS ligand expression during caninevisceral leishmaniosis. Vet. Parasitol. 205, 417-423.

Petito, C.K., Adkins, B., 2005. Choroid plexus selectively accumulates T-lymphocytes in normal controls and after peripheral immune activation. J. Neuroimmunol. 162, 19-27.

Pinelli, E., Gonzalo, R.M., Boog, C.J., Rutten, V.P., Gebhard, D., del Real, G., Ruitenberg, E.J., 1995. Leishmania infantum-specific T cell linesderived from asymptomatic dogs that lyse infected macrophages in amajor histocompatibility complex-restricted manner. Eur. J. Immunol. 25 1594-1600.

Reis, A.B., Teixeira-Carvalho, A., Giunchetti, R.C., Guerra, L.L., Carvalho, M.G. Mayrink, W., Genaro, O., Corrêa-Oliveira, R., Martins-Filho, O.A., 2006. Phenotypic features of circulating leucocytes as immunological markers for clinical status and bone marrow parasite density in dogs naturally infected by Leishmania chagasi. Clin. Exp. Immunol. 146, 303-311.

São Paulo Secretaria de Estado da Saúde de São Paulo (SES-SP), Superintendência de Controle de Endemias (SUCEN), Coordenadoria de Controle de Doenças (CCD), 2006. Manual de Vigilância e Controle da Leishmaniose Visceral Americana do Estado de São Paulo. SES-SP, São Paulo (161pp.).
Saalmuller, A., Werner, T., Fachinger, V., 2002. T-helper cells from naive to commited. Vet. Immunol. Immunopathol. 87, 137-145.

Schenkel, J.M., Zloza, A., Li, W., Narasipura, S.D., Al-Harthi, L., 2010. ß-Catenin signaling mediates CD4 expression on mature CD8+ T cells. J. Immunol. 185 (4), 2013-2019

Schwerk, C., Tenenbaum, T., Kim, K.S., Schroten, H., 2015. The choroid plexus-a multi-role player during infectious diseases of the CNS. Front. Cell Neurosci. 12 (9), 80.

Solano-Gallego, L., Miro, G., Koutinas, A., Cardoso, L., Pennisi, M.G., Ferrer, L., Bourdeau, P., Oliva, G., Baneth, G., 2011. LeishVet guidelines for the practical management of canine leishmaniosis. Parasit. Vectors 4 (1), 86

Strazielle, N., Ghersi-Egea, J.F., 2000. Choroid plexus in the central nervous system: biology and physiopathology. J. Neuropathol. Exp. Neurol. 59, 561-574.

Tipold, A., Moore, P., Jungi, T.W., Sager, H., Vandevelde, M., 1998. Lymphocyte subsets and CD45RA positive T-cells in normal canine cerebrospinal fluid. J. Neuroimmunol. 82, 90-95.

Viñuelas, J., Garcia-Alonso, M., Ferrando, L., Navarrete, I., Molano, I., Mirón, C., Carcelén, J., Alonso, C., Nieto, C.G., 2001. Meningeal leishmaniosis induced by Leishmania infantum in naturally infected dogs. Vet. Parasitol. 101, 23-27.

Watabe, A., Fukumoto, S., Komatsu, T., Endo, Y., Kadosawa, T., 2011. Alterations of lymphocyte subpopulations in healthy dogs with aging and in dogs with cancer. Vet. Immunol. Immunopathol. 142, 189-200.

Wherry, E.J., 2011. T cell exhaustion. Nat. Immunol. 12 (6), 492-499. 